\title{
Evaluation of sexual function in Brazilian women with and without chronic pelvic pain
}

\section{Rosa Azevedo Da Luz' José Miguel de Deus ${ }^{1,2}$ Ana LR Valadares ${ }^{3}$ Délio Marques Conde ${ }^{2}$}

'Women's Health Unit, Teaching Hospital, Federal University of Goiás, Goiânia, Goiás, Brazil; '2Department of Gynecology and Obstetrics, Federal University of Goiás, Goiânia, Goiás, Brazil; 'Department of Gynecology and Obstetrics, State University of Campinas (UNICAMP), Campinas, São Paulo, Brazil
Correspondence: Délio Marques Conde Department of Gynecology and Obstetrics, Universidade Federal de Goiás, Rua 235, S/N, Setor Leste Universitário, 74605-050, Goiânia, GO, Brazil

Tel +55 6232096151

Email delioconde@gmail.com
This article was published in the following Dove Press journal: Journal of Pain Research

\begin{abstract}
Purpose: The aim of this study was to evaluate sexual function in women with chronic pelvic pain (CPP) compared to a control group without CPP and to investigate the factors associated with sexual dysfunction in women with CPP.
\end{abstract}

Methods: This cross-sectional study included 100 women with CPP and 100 controls. Sexual function was evaluated using the Female Sexual Function Index (FSFI) and depression and anxiety using the Hospital Anxiety and Depression Scale (HADS). A generalized linear model was used to compare the groups with respect to the overall FSFI score and the scores obtained for each FSFI domain. Multiple logistic regression analysis was used to identify the factors associated with sexual dysfunction in the study group.

Results: Anxiety was present in $66.0 \%$ of women with CPP in the study group compared to $49.0 \%$ of the controls $(P=0.022)$. Depression was detected in $63.0 \%$ of women with CPP in the study group and in $38.0 \%$ of the controls $(P=0.001)$. Sexual dysfunction was identified in $81.0 \%$ of the women with CPP in the study group compared to $58.0 \%$ of the controls $(P=0.003)$. Following adjustment, the women with CPP had significantly lower mean scores compared to the controls in the FSFI domains of desire ( $3.0 \pm 1.3$ vs $3.6 \pm 1.3 ; P=0.038$ ), arousal (2.6 \pm 1.6 vs $3.4 \pm 1.9 ; P=0.002)$, lubrication $(3.2 \pm 1.9$ vs $3.7 \pm 2.3 ; P=0.011)$, orgasm $(3.0 \pm 1.9$ vs $3.6 \pm 2.2 ; P<0.002)$, and pain $(2.5 \pm 1.7$ vs $3.4 \pm 2.2 ; P<0.001)$. There was no difference between the groups for the satisfaction domain $(P=0.337)$ or for the overall score $(P=0.252)$. A positive and independent association was found between depression and sexual dysfunction in the women with $\mathrm{CPP}(P=0.012)$.

Conclusion: In the women with CPP, sexual dysfunction was more common, and the scores in most of the sexual function domains were poorer than in the control group. Concurrently, depression was found to be positively associated with sexual dysfunction in the women with CPP. Keywords: pain, orgasm, sexual dysfunction, depression, sexuality

\section{Introduction}

Chronic pelvic pain (CPP) in women is a complex and incapacitating condition that can be defined as noncyclic pain of at least 6 months duration in the pelvic region. The source of pain may be the anterior abdominal wall at or below the umbilicus or the lumbosacral back or buttocks. The severity of CPP is sufficient to cause functional disability or to require medical care. ${ }^{1}$ In population-based studies, the prevalence of CPP in women has been reported as $6.4 \%$ in Mexico, $19 \%$ in Brazil, and $25.4 \%$ in New Zealand. ${ }^{2-4}$

CPP may be associated with changes in the gastrointestinal, urological, gynecological, musculoskeletal, and neurological systems, and it may also be associated 
with psychological factors. In a substantial number of women, however, the cause of CPP may remain unidentified. ${ }^{5}$ CPP can exert a negative effect on various aspects of a woman's life, placing limitations on her activities of daily living and her social and work-related activities, as well as giving rise to postural problems and sleep and mood disorders, with a negative effect on her quality of life and sexual function. ${ }^{6-9}$

Sexual function is a vital element in a woman's life that involves a complex interaction among biological, sociocultural, and psychological factors. Sexual dysfunction consists of a heterogenous group of disorders characterized by a clinically significant disturbance in a person's ability to respond sexually or to experience sexual pleasure. An individual may have several sexual dysfunctions at the same time. The Diagnostic and Statistical Manual of Mental Disorders, fifth edition, classifies female sexual dysfunction as a sexual interest/arousal disorder, orgasmic disorder, or genitopelvic pain/penetration disorder. ${ }^{10}$ The etiology of sexual dysfunction is often unknown or presumed to be multifactorial. ${ }^{11}$

Previous studies have shown that women with CPP have more sexual problems than those without CPP.,7,12-15 The reported sexual difficulties include those related to desire, arousal, lubrication, frequency, sexual avoidance, and lack of expression of sexuality. ${ }^{6,7,13,15}$ Furthermore, a greater prevalence of sexual problems has been found in women with CPP compared to those with other types of chronic pains. ${ }^{12,16}$ An association has been reported between sexual dysfunction and mood disorders, a history of sexual abuse, age, family income, and the duration of the pain in women with CPP. ${ }^{13,15}$

Therefore, the objectives of the present study were to compare the sexual function of women with CPP with that of a control group of women without CPP and to investigate the factors associated with sexual dysfunction in the women with CPP.

\section{Patients and methods Sample size}

Sample size was calculated based on the scores obtained for the Female Sexual Function Index (FSFI), considering each domain individually and the overall score, and the prevalence of sexual dysfunction in two groups of women, one with CPP and one without CPP. ${ }^{13}$ The highest required sample size was for the lubrication domain, whose SD was 1.52 , with a difference between the mean scores in the two groups of $0.68 .{ }^{13}$ For an alpha of $5 \%$ and a beta of $20 \%$, the sample size required was calculated as at least 79 women in each of the two groups. ${ }^{17}$

\section{Participants}

This cross-sectional study was conducted from October 2014 to February 2016 at the Department of Obstetrics and Gynecology, Federal University of Goiás Teaching Hospital, Goiânia, Goiás, Brazil. The institution's internal review board approved the study protocol, and all the women signed a written informed consent form prior to their inclusion in the study. The interviews were conducted in a private room, behind closed doors, with only the interviewer and the participant in the room. The participants' rights to confidentiality were respected. Only the investigators had access to the data collected.

A description of how the participants were selected, as well as their sociodemographic, behavioral, and clinical characteristics, has already been published in full in the previous article in which the quality of life of women with CPP and the factors associated with quality of life were described. ${ }^{8}$ Briefly, women $\geq 18$ years of age with a complaint of CPP, who were being followed up as outpatients and who reported being in heterosexual relationships, were invited to participate in the study. The causes of CPP fall beyond the scope of this study and were not evaluated. The control group consisted of women of at least 18 years of age without CPP who were being seen for benign gynecological diseases. Pregnant women, those who reported having been pregnant in the preceding 12 months, and those with a history of cancer were excluded from the study. The study consisted of 100 women with CPP and 100 controls.

In this health care facility, the treatment of women with CPP involves providing guidance on lifestyle with recommendations to include fiber in their diet and to practice physical activity, as well as pharmacological treatment, psychotherapy, and, in certain cases, surgery. Once a specific diagnosis is made, the treatment is directed at the disease. The appropriate pharmacological treatment is selected as follows: if pelvic pain increases in the premenstrual phase or if the woman suffers mood swings at that time, the initial treatment is inducing amenorrhea through the use of hormonal contraceptives (combined estrogen/progestogen or progestogen alone). If the patient has neuralgia, osteomuscular pain, fibromyalgia, or anxiety and/or depression, treatment begins with amitriptyline or other antidepressants, as tolerated by the patient. Gamma-amino butyric acid (GABA) analogs (gabapentin and pregabalin) are indicated when neuropathic pain is suspected. NSAIDs are indicated 
for episodes of acute pain. If there is no improvement in the pain after the use of NSAID, tramadol or codeine is then prescribed. In addition, cognitive behavioral therapy and family constellations are recommended. Surgery is indicated in refractory cases and/or in the case of intolerance to previous treatments and when there is a bowel obstruction resulting from endometriosis or if there is an ovarian endometrioma over $4 \mathrm{~cm}$ in size and if the woman wishes to conceive.

\section{Self-report questionnaires Sexual functioning}

The FSFI is used to assess female sexual function in the 4 weeks prior to consultation. It consists of six domains: desire, arousal, lubrication, orgasm, satisfaction, and pain. Higher scores are indicative of better sexual function. ${ }^{18}$ The FSFI has been translated and validated for use in Brazilian Portuguese. ${ }^{19}$ An overall FSFI score of $\leq 26.55$ was defined as the cutoff point for a definition of sexual dysfunction. ${ }^{20}$

\section{Anxiety and depression}

Anxiety and depression were investigated using the Hospital Anxiety and Depression Scale (HADS). ${ }^{21}$ The HADS has been validated for use in Brazilian Portuguese. A cutoff point of $\geq 8$ was used to identify anxiety and depression. ${ }^{22}$

\section{Statistical analyses}

For the data analysis, CPP constituted the principal independent variable, while the dependent variables were the scores from the six domains of the FSFI, the overall FSFI score, and the presence of sexual dysfunction (overall score, $\leq 26.55$ ). The sociodemographic, behavioral, and clinical characteristics were considered as confounding variables. Results are presented as mean and SDs and median, or as absolute frequencies and percentages. The unpaired, two-sided Student's $t$-test, the chi-squared test, and the Mann-Whitney test were used to compare the characteristics between the groups. A generalized linear model (GLM) was used to compare the FSFI scores between groups, including the scores obtained for each domain and the overall score, with adjustment for potential confounding variables. ${ }^{23}$ A multiple logistic regression analysis was also conducted to compare the prevalence of sexual dysfunction in women with and without CPP following adjustment. The backward selection criteria method was used to identify the factors associated with sexual dysfunction, and estimated coefficients and the standard error of the coefficient were calculated. The variable group (with $\mathrm{CPP} /$ without $\mathrm{CPP}$ ) was maintained in all the regression models. For the statistical analyses, the SPSS statistical software program, version 20.0, was used. Significance level was set at $P<0.05$.

\section{Results}

The age of the participants in the study group was 37.8 \pm 8.0 years (mean $\pm \mathrm{SD}$ ) compared to $37.2 \pm 9.6$ years for the women in the control group $(P=0.648)$. Overall, $16 \%$ of the women with CPP were classified as smokers compared to $6 \%$ of the controls $(P=0.042$; Table 1$)$.

The prevalence of sexual dysfunction was $81.0 \%$ in the women with CPP and $58.0 \%$ in the controls $(P=0.003$; Table 2 ). For the women in the study group, the mean duration of pain was $7.0 \pm 6.0$ years and the mean intensity of the pain was $7.8 \pm 2.1$. In the adjusted analysis, the women with CPP had lower FSFI scores in most of the domains with the exception of the satisfaction domain $(P=0.337)$ and the overall FSFI score $(P=0.252$; Table 3$)$.

Following logistic regression analysis, a significant, independent and positive association was found between depression and sexual dysfunction in the women with CPP $(P=0.012$; Table 4).

\section{Discussion}

The prevalence of sexual dysfunction in the general female population has been reported as $49 \%$ in Brazil, $43 \%$ in USA, and $63.3 \%$ in China. ${ }^{24-26}$ In the present study, the prevalence of sexual dysfunction was $81.0 \%$ in the women with CPP and $58.0 \%$ in those without CPP. Likewise, other authors have found sexual problems to be more common in the women with CPP compared to those without CPP. ${ }^{6,7,12-15}$ Evaluated using the FSFI, the rate of sexual dysfunction was reported as $67.8 \%$ in Turkish women with CPP compared to $32.2 \%$ in the control group. ${ }^{13}$ Collett et al ${ }^{12}$ found that the women with CPP were more likely to have dyspareunia, to have lost interest in sex, and to experience post-coital pain and vaginismus compared to the women with chronic nonpelvic pain and pain-free women, confirming the results of the present study. Other authors found a greater frequency of sexual dysfunction in women with CPP compared to the women with chronic migraine headache. ${ }^{16}$ The concomitant occurrence of CPP and sexual dysfunction suggests that the two conditions share some underlying pathways or risk factors.

Women with CPP were found to have significantly lower scores in the majority of the FSFI domains (desire, arousal, lubrication, orgasm, and pain), with the exception of the satisfaction domain and the overall score. In line with these present findings, a previous study failed to find any statistically significant difference in the satisfaction domain between 
Table I The sociodemographic and clinical characteristics of women with and without CPP

\begin{tabular}{|c|c|c|c|}
\hline Characteristics & $\operatorname{CPP}(n=100)$ & Controls $(n=100)$ & $P$-value \\
\hline Age (years) ${ }^{\mathrm{a}}$ & $37.8 \pm 8.0$ & $37.2 \pm 9.6$ & $0.648^{b}$ \\
\hline Marital status ${ }^{c}$ & & & $0.243^{d}$ \\
\hline With partner & 67.0 & 58.0 & \\
\hline Without partner & 33.0 & 42.0 & \\
\hline Body mass index $\left(\mathrm{kg} / \mathrm{m}^{2}\right)^{\mathrm{a}}$ & $25.6 \pm 4.8$ & $26.7 \pm 6.0$ & $0.245^{e}$ \\
\hline Parity & & & $0.074^{d}$ \\
\hline 0 & 14.0 & 25.0 & \\
\hline$\geq 1$ & 86.0 & 75.0 & \\
\hline Smoker ${ }^{c}$ & & & $0.042^{\mathrm{d}}$ \\
\hline Yes & 16.0 & 6.0 & \\
\hline No & 84.0 & 94.0 & \\
\hline Monthly family income $(R \$)^{a}$ & $1,931.3 \pm 1,237.6$ & $1,867.4 \pm 1,063.3$ & $0.958^{e}$ \\
\hline Employment status ${ }^{c}$ & & & $0.203^{d}$ \\
\hline Employed/performing paid work & 44.0 & 54.0 & \\
\hline Unemployed/retired/homemaker & 56.0 & 46.0 & \\
\hline Anxietyc & & & $0.022^{\mathrm{d}}$ \\
\hline Yes & 66.0 & 49.0 & \\
\hline No & 44.0 & 51.0 & \\
\hline Depression ${ }^{c}$ & & & $0.00 I^{d}$ \\
\hline Yes & 63.0 & 38.0 & \\
\hline No & 37.0 & 62.0 & \\
\hline Menopausal status ${ }^{c}$ & & & $1.000^{\mathrm{d}}$ \\
\hline Premenopausal & 79.0 & 79.0 & \\
\hline Postmenopausal & 21.0 & 21.0 & \\
\hline
\end{tabular}

Notes: ${ }^{a}$ Values are expressed as mean \pm SD. ${ }^{b}$ Student's $t$-test. 'Values are expressed as percentages. ${ }^{d}$ Chi-squared test; ${ }^{e}$ Mann-Whitney test for independent samples. Abbreviation: CPP, chronic pelvic pain.

Table 2 The prevalence of sexual dysfunction in women with and without CPP

\begin{tabular}{|l|l|l|l|}
\hline Group & Prevalence of sexual dysfunction & Unadjusted $\boldsymbol{P}$-value $^{\mathrm{a}}$ & Adjusted $\boldsymbol{P}$-value $^{\mathrm{b}}$ \\
\hline CPP $(\mathrm{n}=100)$ & $81.0 \%$ & 0.001 & 0.003 \\
Controls $(\mathrm{n}=100)$ & $58.0 \%$ & & \\
\hline
\end{tabular}

Notes: ${ }^{a}$ Chi-squared test. ${ }^{b}$ Adjusted using multiple logistic regression analysis for group, age, ethnicity, marital status, monthly family income, schooling, employment status, physical activity, smoking habit, alcohol consumption, parity, menopausal status, body mass index, hypertension, diabetes mellitus, anxiety, and depression. Variables in the final model: depression score, group, and employment status.

Abbreviation: CPP, chronic pelvic pain.

Table 3 Comparison of the FSFI scores in women with and without CPP

\begin{tabular}{|c|c|c|c|c|c|c|}
\hline FSFI domains & Group & Median & Mean & SD & Unadjusted $P$-value ${ }^{a}$ & Adjusted $P$-value \\
\hline \multirow{2}{*}{ Desire } & CPP & 3.0 & 3.0 & 1.3 & \multirow[t]{2}{*}{0.001} & \multirow[t]{2}{*}{0.038} \\
\hline & Controls & 3.6 & 3.6 & 1.3 & & \\
\hline \multirow{2}{*}{ Arousal } & CPP & 2.7 & 2.6 & 1.6 & \multirow[t]{2}{*}{0.001} & \multirow[t]{2}{*}{0.002} \\
\hline & Controls & 3.9 & 3.4 & 1.9 & & \\
\hline \multirow{2}{*}{ Lubrication } & CPP & 3.6 & 3.2 & 1.9 & \multirow[t]{2}{*}{0.018} & \multirow[t]{2}{*}{0.011} \\
\hline & Controls & 4.4 & 3.7 & 2.3 & & \\
\hline \multirow{2}{*}{ Orgasm } & CPP & 3.2 & 3.0 & 1.9 & \multirow[t]{2}{*}{0.008} & \multirow[t]{2}{*}{$<0.002$} \\
\hline & Controls & 4.0 & 3.6 & 2.2 & & \\
\hline \multirow{2}{*}{ Satisfaction } & CPP & 4.0 & 3.8 & 1.4 & \multirow[t]{2}{*}{0.006} & \multirow[t]{2}{*}{0.337} \\
\hline & Controls & 4.8 & 4.4 & 1.4 & & \\
\hline \multirow{2}{*}{ Pain } & CPP & 2.4 & 2.5 & 1.7 & \multirow[t]{2}{*}{0.002} & \multirow[t]{2}{*}{$<0.001$} \\
\hline & Controls & 4.0 & 3.4 & 2.2 & & \\
\hline \multirow{2}{*}{ Overall score } & CPP & 18.6 & 18.1 & 7.9 & \multirow[t]{2}{*}{0.001} & \multirow[t]{2}{*}{0.252} \\
\hline & Controls & 25.0 & 22.1 & 10.3 & & \\
\hline
\end{tabular}

Notes: Mann-Whitney $U$ test for independent samples. 'Multiple regression analysis (gamma distribution). Adjusted using a generalized linear model for group, age, ethnicity, marital status, monthly family income, schooling, employment status, physical activity, smoking habit, alcohol consumption, parity, menopausal status, body mass index, hypertension, diabetes mellitus, anxiety, and depression. Variables in the final model: depression score, group, and employment status.

Abbreviations: CPP, chronic pelvic pain; FSFI, Female Sexual Function Index. 
Table 4 Factors associated with sexual dysfunction in women with chronic pelvic pain $(n=100)$

\begin{tabular}{|l|l|l|l|}
\hline Variables & $\begin{array}{l}\text { Estimated } \\
\text { coefficient }\end{array}$ & $\begin{array}{l}\text { Standard } \\
\text { error of } \\
\text { estimated } \\
\text { coefficient }\end{array}$ & $\boldsymbol{P}_{\text {-value }}$ \\
\hline $\begin{array}{l}\text { Depression (yes) } \\
\text { Constant }\end{array}$ & 1.345 & 0.533 & 0.012 \\
\hline
\end{tabular}

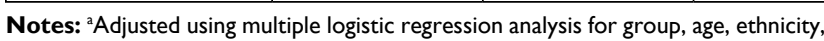
marital status, monthly family income, schooling, employment status, physical activity, smoking habit, alcohol consumption, parity, menopausal status, body mass index, hypertension, diabetes mellitus, anxiety, depression, the intensity of the pain and the duration of the pain. Variable in the final model: depression.

women with and without CPP. On the other hand, there was no difference in the scores obtained for the desire and arousal domains in that same study ${ }^{27}$ Nevertheless, other authors have reported significantly lower scores for all the sexual response domains in women with CPP compared to controls. ${ }^{13}$ Tripoli et $\mathrm{al}^{7}$ conducted a study using the Golombok Rust Inventory of Sexual Satisfaction (GRISS) and found that women with CPP reported significantly less sexual frequency and sexual satisfaction, displayed more sexual avoidance behavior and nonsensuality, and were more likely to complain of vaginismus compared to those without $\mathrm{CPP} .^{28}$ In another study also conducted using the GRISS, Dutch women with CPP were found to exhibit more sexual avoidance behavior and nonsensuality and to be more likely to complain of vaginismus compared to the women without CPP. Nevertheless, there was no statistically significant difference between the groups with respect to sexual frequency, sexual satisfaction, noncommunication, or anorgasmia. ${ }^{15}$ Those authors' results confirm the finding of the present study that there is no difference insofar as the satisfaction domain is concerned.

The satisfaction domain of the FSFI includes three questions that deal, respectively, with the woman's satisfaction with the amount of emotional closeness during sexual activity with her partner, satisfaction with the sexual relationship with her partner, and satisfaction with her sex life in general. These questions seek to capture the woman's perception regarding the quality of her sexual relationship with her partner. Questionnaires such as the FSFI and GRISS offer an objective measurement of sexual function. Nevertheless, when used to evaluate women from different cultural settings, findings may differ. In a study conducted on 213 women with chronic pain of different origins (arthritis, fibromyalgia, endometriosis, physical trauma, and back pain), a positive correlation was found between relationship satisfaction and sexual function. ${ }^{29}$ In this respect, the women with CPP in the present cohort appear to have perceived the quality of the sexual relationship with their partners in a similar way to those without CPP, as shown by the scores in the satisfaction domain. Furthermore, sexual satisfaction may include aspects not covered by the FSFI. In the International Survey of Relationships, sexual satisfaction was investigated in 1,009 midlife couples. ${ }^{30}$ Partners' reports of good health; frequent kissing, cuddling, and caressing; frequent recent sexual activity; attaching importance to one's own and one's partner's orgasm; better sexual functioning; and greater relationship happiness were factors that contributed significantly to being able to predict and understand individuals' sexual satisfaction, showing that the partner matters to an individual's sexual satisfaction. ${ }^{30}$ However, the present study did not include an investigation into partner-related factors.

The mean overall FSFI score was 18.1 for the women with CPP and 22.1 for those without CPP. This difference was statistically significant in the unadjusted analysis; however, significance was lost following adjustment. Some authors have reported significantly lower overall FSFI scores in women with CPP compared to those without CPP, while other investigators failed to find any statistically significant difference between women with deeply infiltrating endometriosis (DIE) and healthy women. ${ }^{13,31}$ Studies conducted in Brazil reported a mean overall FSFI score of 23.4 in women with DIE, 25.51 in women with recurrent vulvovaginal candidiasis (RVVC), and 21.17 in women with localized provoked vulvodynia (LPV). ${ }^{31,32}$ Women in the control group of this study had lower overall FSFI scores than those women in the previous studies whose pain resulted from DIE or RVVC. ${ }^{31,32}$ The reason behind the lower scores in women without CPP is unclear. It could be related to participants' awareness that they have certain benign gynecological conditions, and this may have affected their perception of their sexual function. In addition, the women with CPP in this study also had a lower overall FSFI score than that of the women in previous studies with DIE, RVVC, or LPV. ${ }^{31,32}$ The lack of any statistically significant difference in the overall FSFI score between women with and without CPP in the adjusted analysis suggests that sociodemographic, clinical, and behavioral factors affect the female sexual response, and this hypothesis is supported by the multifactorial nature of sexual function.

CPP in women can be associated with endometriosis, irritable bowel syndrome, pelvic adhesions, and pelvic organ prolapse (POP), among other factors. ${ }^{9} \mathrm{CPP}$ may be caused by POP due to the laxity of the supporting and/or suspending connective tissue structures. ${ }^{33}$ Surgical treatment for POP may improve pelvic pain and quality of life. ${ }^{34,35}$ 
Following surgery for POP, some authors have reported an improvement in sexual function, while others have failed to find any difference or have shown a deterioration in sexual function. ${ }^{35-37}$ In the present study, the presence of POP was not investigated; however, it is important to remember that no statistically significant difference was found between the women with CPP and those without CPP in relation to the factors known to be associated with POP such as age, body mass index, parity, and menopausal status. ${ }^{38}$

Of the various factors that could affect sexual function in women with chronic medical conditions, mood disorders merit particular mention. ${ }^{29,39}$ In the present study, following multiple regression analysis, depression was the only factor that was positively and independently associated with sexual dysfunction in women with CPP. Previous studies have shown an association between depression and sexual dysfunction in women with CPP. ${ }^{15,39}$ However, other authors have found no association and yet others failed to evaluate depression as a possible determinant of sexual dysfunction in women with CPP. ${ }^{6,7,31}$ In agreement with the results of the present study, other previous studies have reported an association between sexual dysfunction and depression in different chronic diseases such as rheumatoid arthritis, fibromyalgia, and multiple sclerosis, although other investigators have found no association. ${ }^{40-42}$ Depression is characterized by the loss of interest, a fall in energy levels, poor self-esteem, and an inability to feel pleasure. Irritability and social withdrawal may impair the individual's ability to form and maintain intimate relationships. This situation may contribute to the occurrence of sexual problems. ${ }^{43}$ The temporal relationship between depression and sexual dysfunction has not been established in the women with CPP, ie, it is not yet known whether sexual dysfunction is a consequence of depression or its cause. Further studies are required to investigate this question.

The findings of the present study should be interpreted in the light of several limitations. Since this is a cross-sectional study, it was not possible to establish a relationship of causality. No investigation was made into the cause of CPP in the study group; however, there are indications that sexual dysfunction is unrelated to the cause of CPP. ${ }^{7}$ Furthermore, in a not inconsiderable number of women, the origin of CPP remains unidentified. ${ }^{1}$ In the present study, partner-related factors; distress caused by sexual disorders; and the use of drugs such as antidepressants, anxiolytics, and anticonvulsants were not evaluated. Further studies designed to investigate these issues may increase understanding of the sex life of women with CPP.
The existence of a control group, which permitted sexual function to be compared between women from the same health care facility, constitutes one of the strong points of this study. The use of instruments commonly employed in healthrelated studies (FSFI and HADS) represents an additional strength. To the best of our knowledge, this is the study with the largest number of potential confounders included in the evaluation of sexual function in women with CPP.

\section{Conclusion}

Sexual dysfunction was more common in the women with CPP compared to those without CPP. Scores for the majority of the sexual function domains (desire, arousal, lubrication, orgasm, and pain) were lower in the women with CPP. However, there was no difference between the groups for the satisfaction domain or with respect to the overall score. Depression was positively and independently associated with sexual dysfunction in the women with CPP. These findings suggest a need for health care professionals to routinely screen for sexual dysfunction in the women with CPP, taking into consideration its association with psychological factors. In this respect, a transdisciplinary approach is required for the women with CPP.

\section{Author contributions}

All authors contributed to data analysis, drafting and revising the article, gave final approval of the version to be published, and agree to be accountable for all aspects of the work.

\section{Disclosure}

The authors report no conflicts of interest in this work.

\section{References}

1. Howard FM. The role of laparoscopy in the chronic pelvic pain patient. Clin Obstet Gynecol. 2003;46(4):749-766.

2. García-Pérez H, Harlow SD, Erdmann CA, Denman C. Pelvic pain and associated characteristics among women in northern Mexico. Int Perspect Sex Reprod Health. 2010;36(2):90-98.

3. Coelho LS, Brito LM, Chein MB, et al. Prevalence and conditions associated with chronic pelvic pain in women from São Luís, Brazil. Braz J Med Biol Res. 2014;47(9):818-825.

4. Grace VM, Zondervan KT. Chronic pelvic pain in New Zealand: prevalence, pain severity, diagnoses and use of the health services. Aust $N Z$ J Public Health. 2004;28(4):369-375.

5. Howard FM. Chronic pelvic pain. Obstet Gynecol. 2003;101(3):594-611.

6. Kaya B, Unal S, Ozenli Y, Gursoy N, Tekiner S, Kafkasli A. Anxiety, depression and sexual dysfunction in women with chronic pelvic pain. Sex Relation Ther. 2006;21(2):187-196.

7. Tripoli TM, Sato H, Sartori MG, de Araujo FF, Girão MJ, Schor E. Evaluation of quality of life and sexual satisfaction in women suffering from chronic pelvic pain with or without endometriosis. J Sex Med. 2011;8(2):497-503.

8. Da Luz RA, de Deus JM, Conde DM. Quality of life and associated factors in Brazilian women with chronic pelvic pain. J Pain Res. 2018;11:1367-1374. 
9. Zondervan KT, Yudkin PL, Vessey MP, et al. The community prevalence of chronic pelvic pain in women and associated illness behaviour. $\mathrm{Br} J$ Gen Pract. 2001;51(468):541-547.

10. American Psychiatric Association. Diagnostic and Statistical Manual for Mental Disorders. 5th ed. Arlington, VA: American Psychiatric Press; 2013.

11. McCabe MP, Sharlip ID, Atalla E, et al. Definitions of Sexual Dysfunctions in Women and Men: A Consensus Statement From the Fourth International Consultation on Sexual Medicine 2015. J Sex Med. 2016;13(2):135-143.

12. Collett BJ, Cordle CJ, Stewart CR, Jagger C. A comparative study of women with chronic pelvic pain, chronic nonpelvic pain and those with no history of pain attending general practitioners. Br J Obstet Gynaecol. 1998;105(1):87-92.

13. Verit FF, Verit A, Yeni E. The prevalence of sexual dysfunction and associated risk factors in women with chronic pelvic pain: a crosssectional study. Arch Gynecol Obstet. 2006;274(5):297-302.

14. Florido J, Pérez-Lucas R, Navarrete L. Sexual behavior and findings on laparoscopy or laparotomy in women with severe chronic pelvic pain Eur J Obstet Gynecol Reprod Biol. 2008;139(2):233-236.

15. ter Kuile MM, Weijenborg PT, Spinhoven P. Sexual functioning in women with chronic pelvic pain: the role of anxiety and depression. $J$ Sex Med. 2010;7(5):1901-1910.

16. Roth RS, Punch MR, Bachman JE. Psychological factors and chronic pelvic pain in women: a comparative study with women with chronic migraine headaches. Health Care Women Int. 2011;32(8):746-761.

17. Pocock SJ. Clinical Trials: A Practical Approach. Chichester: John Wiley and Sons; 1983.

18. Rosen R, Brown C, Heiman J, et al. The Female Sexual Function Index (FSFI): a multidimensional self-report instrument for the assessment of female sexual function. J Sex Marital Ther. 2000;26(2):191-208.

19. Thiel RR, Dambros M, Palma PC, Thiel M, Riccetto CL, Ramos Mde F. Translation into Portuguese, cross-national adaptation and validation of the Female Sexual Function Index. Rev Bras Ginecol Obstet 2008;30(10):504-510. Portuguese.

20. Wiegel M, Meston C, Rosen R. The female sexual function index (FSFI): cross-validation and development of clinical cutoff scores. $J$ Sex Marital Ther. 2005;31(1):1-20.

21. Zigmond AS, Snaith RP. The hospital anxiety and depression scale. Acta Psychiatr Scand. 1983;67(6):361-370.

22. Botega NJ, Pondé MP, Medeiros P, Lima MG, Guerreiro CA. Validation of the Hospital Anxiety and Depression Scale (HADS) in epileptic outpatients. J Bras Psiquiatr. 1998;47(6):285-289.

23. Nelder JA, Wedderburn RWM. Generalized Linear Models. J R Stat Soc Ser A. 1972;135(3):370-384.

24. Abdo CH, Oliveira WM, Moreira ED Jr, Fittipaldi JA. Prevalence of sexual dysfunctions and correlated conditions in a sample of Brazilian women--results of the Brazilian study on sexual behavior (BSSB). Int J Impot Res. 2004;16(2):160-166.

25. Laumann EO, Paik A, Rosen RC. Sexual dysfunction in the United States: prevalence and predictors. JAMA. 1999;281(6):537-544.

26. Lou WJ, Chen B, Zhu L, et al. Prevalence and factors associated with female sexual dysfunction in Beijing, China. Chin Med J (Engl). 2017;130(12):1389-1394.
27. Romão APMS, Gorayeb R, Romão GS, Poli-Neto OB, Nogueira AA. Impact of chronic pelvic pain on female sexual function. Int J Clin Med. 2013;4(3):178-182.

28. Rust J, Golombok S. The GRISS: a psychometric instrument for the assessment of sexual dysfunction. Arch Sex Behav. 1986;15(2): $157-165$.

29. Finn E, Morrison TG, McGuire BE. Correlates of sexual functioning and relationship satisfaction among men and women experiencing chronic pain. Pain Med. 2018;19(5):942-954.

30. Fisher WA, Donahue KL, Long JS, Heiman JR, Rosen RC, Sand MS. Individual and partner correlates of sexual satisfaction and relationship happiness in midlife couples: dyadic analysis of the International Survey of Relationships. Arch Sex Behav. 2015;44(6):1609-1620.

31. Evangelista A, Dantas T, Zendron C, Soares T, Vaz G, Oliveira MA. Sexual function in patients with deep infiltrating endometriosis. J Sex Med. 2014;11(1):140-145.

32. Giraldo PC, Polpeta NC, Juliato CR, Yoshida LP, do Amaral RL, Eleutério Junior J. Evaluation of sexual function in Brazilian women with recurrent vulvovaginal candidiasis and localized provoked vulvodynia J Sex Med. 2012;9(3):805-811.

33. Liedl B, Goeschen K, Durner L. Current treatment of pelvic organ prolapse correlated with chronic pelvic pain, bladder and bowel dysfunction. Curr Opin Urol. 2017;27(3):274-281.

34. Petros PP. Severe chronic pelvic pain in women may be caused by ligamentous laxity in the posterior fornix of the vagina. Aust $N Z J$ Obstet Gynaecol. 1996;36(3):351-354.

35. Caruso S, Bandiera S, Cavallaro A, Cianci S, Vitale SG, Rugolo S. Quality of life and sexual changes after double transobturator tensionfree approach to treat severe cystocele. Eur J Obstet Gynecol Reprod Biol. 2010;151(1):106-109.

36. Pauls RN, Silva WA, Rooney CM, et al. Sexual function after vaginal surgery for pelvic organ prolapse and urinary incontinence. Am JObstet Gynecol. 2007;197(6):622.e1-7.

37. Altman D, Elmér C, Kiilholma P, et al; Nordic Transvaginal Mesh Group. Sexual dysfunction after trocar-guided transvaginal mesh repair of pelvic organ prolapse. Obstet Gynecol. 2009;113(1):127-133.

38. Asresie A, Admassu E, Setegn T. Determinants of pelvic organ prolapse among gynecologic patients in Bahir Dar, North West Ethiopia: a casecontrol study. Int J Womens Health. 2016;8:713-719.

39. Randolph ME, Reddy DM. Sexual functioning in women with chronic pelvic pain: the impact of depression, support, and abuse. J Sex Res. 2006;43(1):38-45.

40. Collado-Mateo D, Olivares PR, Adsuar JC, Gusi N. Impact of fibromyalgia on sexual function in women. J Back Musculoskelet Rehabil. Epub 2018 Mar 09.

41. Dehghan-Nayeri N, Khakbazan Z, Ghafoori F, Nabavi SM. Sexual dysfunction levels in iranian women suffering from multiple sclerosis. Mult Scler Relat Disord. 2017;12:49-53.

42. Nascimento ER, Maia AC, Nardi AE, Silva AC. Sexual dysfunction in arterial hypertension women: The role of depression and anxiety. $J$ Affect Disord. 2015;181:96-100

43. Baldwin DS. Depression and sexual dysfunction. Br Med Bull. 2001;57:81-99.
Journal of Pain Research

\section{Publish your work in this journal}

The Journal of Pain Research is an international, peer reviewed, open access, online journal that welcomes laboratory and clinical findings in the fields of pain research and the prevention and management of pain. Original research, reviews, symposium reports, hypothesis formation and commentaries are all considered for publication.
Dovepress

The manuscript management system is completely online and includes a very quick and fair peer-review system, which is all easy to use. Visit http://www.dovepress.com/testimonials.php to read real quotes from published authors. 